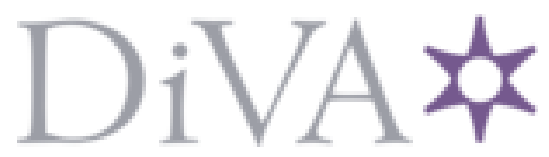

http://www.diva-portal.org

\title{
Postprint
}

This is the accepted version of a paper published in Nordic Journal of Nursing Research. This paper has been peer-reviewed but does not include the final publisher proof-corrections or journal pagination.

Citation for the original published paper (version of record):

Wenneberg, S., Isaksson, A. (2014)

Living with multiple sclerosis: the impact of chronic illness.

Nordic Journal of Nursing Research, 34(3): 23-27

http://dx.doi.org/10.1177/010740831403400306

Access to the published version may require subscription.

N.B. When citing this work, cite the original published paper.

Permanent link to this version:

http://urn.kb.se/resolve?urn=urn:nbn:se:Inu:diva-41775 


\section{Living with multiple sclerosis: The impact of chronic illness}

Stig Wenneberg, PhD, senior lecturer; Ann-Kristin Isaksson, RN, RNT, PhD, senior lecturer;

\section{Authors' version - accepted version of the article - Spring of 2014}

\section{ABSTRACT}

Background: Some patients having multiple sclerosis (MS) still report gains from the adversity of suffering from a chronic and debilitating illness.

Aim: To explore the subjective experiences of quality of life in patients with MS, focusing on possible positive aspects of having to come to terms with MS.

Method: An inductive approach in the form of latent content analysis was used to analyze the data from 61 MS-patient interviews.

Findings: Fighting a losing battle but also gradually conquering oneself was the underlying theme that emerged from the following four main categories: Experience of ill-health, Experience of health in spite of illness, Psychosocial consequences of having MS, and Different ways of managing MS. Patients with MS were forced to re-evaluate their life during the course of illness, gaining hard-earned knowledge that became the basis for continually managing their illness.

Conclusion: Nurses and other health care personnel need to be aware of the impact living with MS has on patients as revealed by the present study in order to be able to help these patients come to terms with and adapt to the deleterious effects of this illness.

Keywords: illness experience, multiple sclerosis, quality of life, social relations, well-being 


\section{INTRODUCTION}

Multiple sclerosis (MS) is a chronic neurological disease with various neurological symptoms. For some patients the disease can be markedly progressive and lead to severe disability, while for others it can be fairly benign, with few relapses and remission of neurological impairment. The onset is primarily within the age-range 20-40 years (1). MS being a progressive disease with an unpredictable prognosis, experience of uncertainty is often reported by patients as being a major emotional distress problem (2). This may negatively influence the patient's illness perception and subsequently also her well-being (3).

One way to estimate how people are living with and experiencing the disease onset and progression is by means of measuring quality of life (QoL), a multidimensional concept involving both objective measurements as well as subjective experiences of health, illness and well-being (4). For instance, self-assessed health-related quality of life includes those aspects of QoL that are directly influenced by disease such as functional and physical abilities, which generally are lower in patients with diseases like MS (5). However, other studies have also shown that reduced QoL is not just solely related to high levels of disability and impairment. Cognitive difficulties and role limitations are also perceived by patients as significantly influencing the subjective experience of well-being and satisfaction with one's situation (6). Furthermore, Malcomson, Lowe-Strong and Dunwoody found, in a qualitative study (7), not only negative experiences related to the initial diagnosis of MS, but also positive ones, related to successfully adapting to the disease.

Interestingly, so-called benefit findings or gains from adversity in patients with medical problems have quite recently been investigated (8). The first report of MS patients' 
benefitting from a positive reappraisal of their illness experience was published in 1999 (9). A successful adaptation to a disabling illness may thus start with a change in the appraisal of the consequences of the illness, being now less and less important in terms of their well-being (10). According to Russel and co-workers (11, p. 67) it is "not unusual for persons with a chronic illness to arrive at an appreciation for certain benefits of learning to live with that illness." However, it could also be a result of more effective supportive care in addition to patient adaptation (12).

Few studies have explored the personal accounts of MS patients who successfully cope with their illness (7). There is a need for more knowledge about their emotional state as well as their subjective experiences in connection with trying to adapt to such a chronic and progressive illness — more specifically, there is a need for more knowledge about how to acquire and maintain a sense of well-being in the face of such a debilitating condition (13).

\section{Aim}

To explore the subjective experiences of quality of life in patients with MS, focusing on possible positive aspects of having to come to terms with this illness.

\section{METHODS}

\section{Study design}

This study employed a qualitative inductive design using latent content analysis to identify variations with regard to similarities and differences in patients' illness experiences and perceived quality of life (14). This study was part of a larger research project, but was not 
included in the work leading to a doctoral thesis (15). The Regional Ethical Review Board, Örebro University Hospital, approved this research project (Dnr 500:16 188/01).

\section{Participants}

The 61 participating patients were recruited from a local MS register. They received written information and were then asked by telephone if they were willing to participate. The patients who accepted to be part of the study were subsequently interviewed. The study group comprised twice as many women than men, see table I for demographics and illness-related factors.

$<<$ Insert table I about here $>>$

\section{Data collection}

The answers to the following three interview questions, that had not previously been analyzed, were the basis of the present study: 1) Do you feel that your illness has changed your quality of life? 2) Has your view of the meaning of quality of life changed because of this illness? 3) Has the illness made any positive contribution to your life? They were gently coaxed to elaborate in case their answers to the questions were not clearly expressed. Fifty-three of the interviews were conducted in the patients' homes; in the other eight cases the patient preferred to come to a secluded room at the hospital. All the interviews were conducted in the form of conversation and were recorded by the second author of the present study, AKI. Thereafter they were transcribed verbatim, including expressions of emotion. The duration of an interview was about 30-45 minutes, out of which the abovementioned three questions were used in the present study (15). 


\section{Data analysis}

Initially the text was read several times in order to get a sense of the whole. The interview material was then divided into meaning units in accordance with the process of inductive content analysis described by Graneheim and Lundman (16). Each meaning unit was condensed to preserve its essence and keep as close as possible to the original wording. The next step involved a coding process where the underlying meaning of each unit was captured by providing it with a descriptive code. This facilitated the collection of similar codes into different sub-categories, which at the end were sorted into main categories (16). The interpretation and categorization were discussed among the authors of this study until agreement was reached. Thus together the authors scrutinized the development of categories and sub-categories from the empirical material until it was certain that no core content was missed or overlooked. An underlying theme was then formulated based on the content of the main categories together with the overall text material, expressing the main latent content of the analyzed text (16).

In the presentation of the results, patient quotations are used to illustrate each sub-category. These quotations from the participating subjects were carefully selected as being trustworthy representations of the core content of each sub-category. See table II for examples of the different steps of analysis.

>>>> Insert table II about here $<<<<<<<<$ 


\section{Ethical considerations}

The patients were sent written information about the research project and had time to reflect before being asked about their willingness to participate. In conjunction with the phone call they were given more information and given the opportunity to put questions directly to the researcher. They were informed both in writing and orally that they were in no way obliged to be part of the study and, if participating, could withdraw at any time without needing to provide any explanation. The regular care would not be affected by their participating or not. Ethical approval was received from the prior to the study. Confidentiality was assured, and the quotations have been selected carefully so as to preserve anonymity.

\section{RESULTS}

The results point to an underlying theme; Fighting a losing battle but also gradually conquering oneself, (Table II). Four main categories (with associated sub-categories) are also presented: (1) Experience of ill-health, (2) Experience of health in spite of illness, (3) Psychosocial consequences of having MS, and (4) Different ways of managing MS.

(1) Experience of ill-health. Two sub-categories emerged: (a) Negative existential impact; and (b) Physical limitations affecting quality of life.

\section{Negative existential impact}

MS has deeply affected most of the patients and it was difficult for the participants to find anything inherently positive when living with this illness. Thus it was a challenge to handle the impact of this chronic and debilitating condition, both emotionally and physically. Brooding over the meaning of life when suffering from MS sometimes could give rise to 
existential anxiety. In the case of certain patients, MS transformed their life completely in a negative way and hindered them in many ways. Being forced to lower their level of ambition in life could lead to a questioning of their life's purpose. The illness gradually took over one's life or was at the very least an ever-present background against which one’s life was lived.

But then I've always been a happy and positive sort of person, although... - well, I still am, ... but I'm not happy deep down, you might say. But you can't just sit and whine, it's no good. So you don't.

Physical limitations affecting quality of life

Not having the same physical stamina and endurance as before was perplexing and frustrating. To accept the disabling effects was tough, though some of the patients kept their hopes of a better future and continued fighting a losing battle. Psychologically, this process was anything but easy when MS so clearly influenced so many aspects of life.

But of course I feel my quality of life's become very restricted by the fact that I can't move. Yes, a lot of things we used to do are gone, so a lot of the quality of my life's gone too.

Thus overall quality of life was substantially affected, mainly through the impact of MS on physical mobility and the ability to walk, with the accompanying sense of decreased autonomy in work and everyday life. Work and leisure activities such as gardening and sport were influenced to a greater or lesser extent and patients often had to abstain from these activities. 
(2) Experience of health in spite of illness. Three sub-categories emerged: (a) Acquiring illness insight; (b) A more quiescent life-style; and (c) Life appreciation in spite of MS.

\section{Acquiring illness insight}

Though having a serious, progressing illness has left its mark on the patients, at the same time they acquired knowledge otherwise difficult to come by. All gained a new perspective on life since they were being forced to come to terms with themselves, their life and their illness. This could be appreciated by these patients in an almost detached manner. It was a question of having discovered what might be described as a new life — a life influenced by illness. Thus a process of re-orientation had started, where it even was considered a gift to have had to suffer through a whole range of experiences. The pendulum swung between illness and health, bad spells and temporary recovery.

I know what it's like when you're sort of right in the middle of a bad bout and you maybe don't feel at all well, then it's sort of just gone away and you feel all right — and of course you see a big difference. Then you can do just what you want - you can, well, move about and get on your bike and go and see a mate.

\section{A more quiescent life-style}

Re-orientation could also be seen in the form of a gentler and quieter life style. Work and career did not have the same high priority as before, ceding precedence to such things as being at home or engaging in relaxing leisure activities. Their limited physical functioning indeed forced these persons to relax and take things more easily, and there were those who spoke of now actually feeling better emotionally than before becoming ill. Not having so 
much stress in one’s life fostered a certain attitude: finally it was possible to, as it were, "to smell the roses.”

Well, it's sort of pleasanter now, you might say. My life's probably pleasanter. Feels better in some way - the situation's what it is, but in many ways I feel better inside than I used to. Calmer, I think. Yes, that's it. I should think I just make the most of the good parts.

Life appreciation in spite of MS

If these patients somehow were able to consider the experience of MS as positive, they were able to really start appreciating life itself and its gifts. For example, having a fairly wellfunctioning body in spite of having MS was appreciated: whatever still worked in the body was now given particular notice. The ability to enjoy nature was also noted. An attitude of gratitude could even be detected in some of the interviews - gratitude for what still could be enjoyed of life.

You've got to be glad, haven't you, that you can even... - that things are as they are. And so I think, well, it's not worse, so there's a positive side to it. I mean, I can move and I can be as I am. But of course it can change fast, you don't know... but anyway...

(3) Psychosocial consequences of having MS. Two sub-categories emerged: (a) Increased empathy for others' suffering; and (b) Diverging effects seen in social interactions. 
Increased empathy for others' suffering

Their own trials and tribulations in respect of MS gave the patients plenty of empathy and understanding when it came to other sick people. Humility developed naturally, and others were not judged as quickly as before. Thus the patients' increasing tolerance for others who suffered was a result of their having themselves been through the torment of illness.

You can understand other people with illnesses and that, of course you can. Before, life just went its ordinary way, and I think about that sometimes when people don't understand me. I mean, if they haven't gone through something themselves it's very hard for them to put themselves in your position.

\section{Diverging effects seen in social interactions}

None of the patients wanted pity or to be judged as a disabled person. They chose rather to isolate themselves, avoiding company and attention. Lack of energy and limited physical ability was a hindrance to enjoying the company of others on a basis of equality — it was hard to come to terms with the difference deriving from having or not having a chronic illness. Quality of life in terms of social interactions was in jeopardy in some patients in that they had a real social vulnerability due to the deterioration of their physical proficiency.

I'd like to meet a lot of my friends a lot more often. But really there are only a few of them left, because I just haven't got the energy to keep in touch with all the people I'd like to keep in touch with. I can't give as much of myself, it's not there to give [29]. 
However, having MS could also offer an opportunity for new social contacts, for instance, with other patients going through rehabilitation or through specific MS organizations. When the focus shifted from job and career to family and friends, this naturally fostered closer relationships and an enhanced appreciation for other people.

It's been such a surprise to me that you can get new friends at my age. I didn't think it'd be like that, I thought it'd be quite the opposite. But perhaps the illness — and thinking about life being short and all that — has made it easier for me to talk to other people. Which has made it easier to make friends.

(4) Different ways of managing MS. Two sub-categories emerged: (a) Minimizing the illness impact and (b) Experiences and acquired strategies that facilitate daily life.

Minimizing the illness impact

One way to deal with MS was to attempt to minimize its influence. For instance, patients carried on as usual with their work and personal life despite the difficulties deriving from physical restriction and lack of energy. Furthermore, patients tried to adapt emotionally to illness-imposed limitations by, as far as possible, "standing above” them. Living life as usual in spite of relapses and not giving too much attention to MS seemed to be a normal mechanism for handling their illness-related problems.

No, it hasn't [changed the quality of my life]. I mean, every time I've had a bad spell I go on living afterwards the same way I did before. 
Experiences and acquired strategies that facilitate daily life

The illness experiences were in themselves a way to strengthen the patients by "toughening them up.” Self-development, persistence, getting to know themselves in difficult situations — these things could help them to gain inner strength and tap more into their own inner resources. Adapting to the situation, planning their activities in advance and using aids of all kinds to solve illness-related problems supported them in their desire to live a fairly full and autonomous life in spite of having MS. Various training programs and rehabilitative exercises were also considered helpful. This process was recounted as being for the most part a positive experience, even though (as previously mentioned) the patients had to come to terms with their limitations, both at home and at work. The fact that time was now perceived as being quite limited urged them on to more quickly realize their goals and desires.

But I see to it, sort of all the time that things get done - because you never know... And I think that's tough. And I suppose there's a bit of a quality of life aspect to everything I do: Oh... I'd better... - now my hands feel all right, so let's do that bit of moving as fast as we can, because you never know...

\section{DISCUSSION}

The underlying theme that emerged from the results of this study, Fighting a losing battle but also gradually conquering oneself, recognizes the possibility of living quite a full life despite the presence of a "foe" - multiple sclerosis. The struggle against this chronic and progressive disease is not winnable; the focus must thus also be on the patient's ability to benefit from the experiences of successfully handling illness-related limitations. In this sense the patient must "conquer" herself/himself rather than the disease itself. 
Each main category and associated sub-categories provided pieces of the puzzle to more fully understand the complexity of living with MS. This was a continual challenge and patients were forced to face the consequences of having a malfunctioning body which ultimately affected all aspects of their lives. The often severe limitations faced by these patients increased their frustration, and influenced their emotional life as well as their everyday life, as has previously been noted (7).

Not being able to take anything for granted, a new outlook or re-orientation was evident in the present study. Indeed, MS-patients must try to incorporate the reality of MS into their personal, family and working lives in order to facilitate the management of MS symptoms as other research groups have pointed out $(17,18)$. This means rethinking their expectations and priorities in life. What do they want from life and how can they reach their goals if their symptoms can be managed fairly effectively? If the illness is kept in check, there is a chance to live one's life without MS being the dominating life experience as reported by others (13).

In addition, there seems to be a re-direction towards a more quiescent life-style and an appreciation for life itself in the present study. Women with MS in another study describe this as "taking it slowly and finding an atmosphere of rest, relaxation, and being present in the moment” (13, p. 1257). This emphasizes the importance of “let the control go" as highlighted by Ironside et al. (18), of not resigning or giving up but instead learning from one's experiences to at least try to live a full life in spite of having a chronic illness. However, a well-meaning piece of advice from a nurse to make the most of the situation may not be sufficient or even suitable (19) - rather it is a question of the patient's attitude or outlook attained from the long-term process of adaptation to illness. 
The patients in the present study relied increasingly on others, trying to strengthen social ties especially with close friends and family. In addition, other friends with MS played an important social role, as they did in a study by Fong and co-workers (20). Other social roles than the worker role became more important. An increased tolerance and acceptance of others was also forged by their own suffering. However, since persons with MS are usually limited in some respect by physical disability (and eventual mental disability), natural social interactions with other people are threatened.

The participants in this study expressed their intention to continue living "like a normal person” despite frequently having illness symptoms such as fatigue, downplaying the severity of their symptoms. However, Thorne and co-workers (17) also describe how the efforts to minimize the impact of symptoms can be complicated by the unpredictable nature of MS. The ability to adapt successfully to changes thus also brought about by a progressive disease thus also requires a personal transformation leading to "growing confidence in their ability to handle adversity” (21, p. 190). This was also evident in the current study where the participants continuously had to adapt to their present illness condition, chiseling out usable strategies to handle the daily challenge of living with MS.

Furthermore, it is interesting to compare the current results with those of other studies, especially with regard to benefit findings. Factors such as Personal growth, Change in priorities/goals, Appreciation of life and Strengthening of relationships were also seen in another qualitative study using content analysis (19), which is in line with our own results. This warrants further studies in this area. 


\section{Methodological considerations}

This study involved 61 interviews which provided material rich in variation of experiences. Since the interview questions were few it also permitted depth and focus in the analysis. Sandelowski (22) describes the advantages of having material comprehensive enough to offer rich variation in the data but also small enough to allow deep data analysis. It was also perceived that the aim of the study with regard to the three main interview questions was answered. Another advantage of the relatively large number of patients enrolled is a possible increase in transferability of the findings to other areas of interest. Furthermore, the dependability of the results was secured by the second author (AKI). She has checked the plausibility of the generated codes and corresponding sub-categories, main categories and underlying theme in the data, enhancing the quality of the results. Authentic quotations have also been used to increase the study's trustworthiness (16). In addition, examples of the analysis process have been provided, which also increased the trustworthiness of the results.

\section{Conclusion}

The underlying theme of this study's result Fighting a losing battle but also gradually conquering oneself represents the illness-related experiences of 61 MS-patients trying to live with this illness. It is an arduous and complex process of adaptation with the accompanying intertwined negative and positive experiences. Nurses and other health care staff such as social workers could help MS-patients live a fuller and more gratifying life by building upon the patients’ own particular strengths and resources. For instance, the development of educational programs tailored to this patient group could focus on different ways of managing the impact of the illness as identified by this study. 
Accepted for publication 11.03.2014

Stig Wenneberg, PhD, senior lecturer, Linnaeus University, Sweden.

Ann-Kristin Isaksson, RN, RNT, PhD, senior lecturer, Örebro University, Sweden.

Corresponding author: Stig Wenneberg, School of Health and Caring sciences, Linnaeus

University, SE-351 95 Växjö. Telephone number: +46 (0) 470-708209

E-mail: stig.wenneberg@lnu.se 


\section{REFERENCES}

1. Olek MJ, Dawson DM. Multiple sclerosis and other inflammatory demyelinating diseases of the central nervous system In: Bradley WG, Daroff RB, Fenichel GM, Marsden CD, editors. Neurology in Clinical Practice, 3rd ed. Boston: Butterworth-Heinemann; 2000; p. $1431-1465$

2. Gulick EE. Emotional distress and activities of daily living functioning in persons with multiple sclerosis. Nursing Research 2001; 50(3):147-154.

3. Siegert RJ, Abernethy DA. Depression and multiple sclerosis: a review. Journal of Neurology Neurosurgery \& Psychiatry 2005; 76(4):469-475.

4. Mitchell AJ, Benito-León J, Morales Gonzalez J-M, Rivera-Navarro J. Quality of life and its assessment in multiple sclerosis: integrating physical and psychological component of wellbeing. Lancet Neurology 2005; 4:556-566.

5. Nortvedt MW, Riise T. The use of quality of life measures in multiple sclerosis research. Multiple Sclerosis 2003; 9:63-72.

6. Benito-Leon J, Morales JM, Rivera-Navarro J. A review about the impact of multiple sclerosis on health-related quality of life. Disability and Rehabilitation 2003; 25(3):12911303.

7. Malcomson KS, Lowe-Strong AS, Dunwoody L. What can we learn from the personal insights of individuals living and coping with multiple sclerosis? Disability and Rehabilitation 2008; 30(9):662-674.

8. Pakenham KI. Benefit finding in multiple sclerosis and its association with positive and negative outcomes. Health Psychology 2005; 24(2):123-132. 
9. Mohr DC, Dick LP, Russo D, Pinn J, Boudewyn AC, Likosky W. The psychological impact of multiple sclerosis: exploring the patient's perspective. Health Psychology: Official Journal of the Division of Health Psychology 1999; 18(4):376-382.

10. Murell R. Quality of life and neurological illness. A review of the literature. Neuropsychological Review 1999; 9(4):209-229.

11. Russel CS, White MB, White CP. Why me? Why now? Why multiple sclerosis? Making meaning and perceived quality of life in a Midwestern sample of patients with multiple sclerosis. Families, Systems \& Health 2006; 24(1):65-81.

12. Hopman WM, Coo H, Pavlov A, Day AG, Edgar CM, McBride EV, Brunet DG. Multiple sclerosis: Change in health-related quality of life over two years. The Canadian Journal of Neurological Sciences 2009; 36:554-561.

13. Olsson M, Skär L, Söderberg S. Meaning of feeling well for women with multiple sclerosis. Qualitative Health Research 2010; 20(9):1254-1261.

14. Lundman B, Hällgren Graneheim U: Kvalitativ innehållsanalys. I: Tillämpad kvalitativ forskning inom hälso- och sjukvård. Granskär M \& Höglund-Nielsen (editors). Lund: Studentlitteratur; 2008. P. 159-172.

15. Isaksson A-K. Chronic sorrow and quality of life in patients with multiple sclerosis. [doctoral thesis]. Örebro Studies in Caring Sciences 12. School of Health and Medical Sciences, Örebro University, Sweden; 2007.

16. Graneheim UH, Lundman B. Qualitative content analysis in nursing research: Concepts, procedures and measures to achieve trustworthiness. Nurse Education Today 2004; 24(2):105-112.

17. Thorne S, Con A, McGuiness G, McPherson G, Harris SR. Health care communication issues in multiple sclerosis: an interpretive description. Qualitative Health Research 2004; 14(1):5-22. 
18. Ironside PM, Scheckel M, Wessels C, Bailey ME, Powers S, Seeley, DK. Experiencing chronic illness: Co-creating new understandings. Qualitative Health Research 2003; 13(2):171-183.

19. Pakenham, KI. The nature of benefit findings in multiple sclerosis (MS). Psychology, Health \& Medicine 2007; 12:190-196.

20. Fong T, Finlayson M, Peacock N. The social experience of aging with a chronic illness: Perspectives of older adults with multiple sclerosis. Disability and Rehabilitation 2006; 28(11):695-705.

21. Kirkpatrick Pinson DM, Ottens AJ, Fisher TA. Women coping successfully with multiple sclerosis and the precursors of change. Qualitative Health Research 2009; 19(2):181-193.

22. Sandelowski M. Qualitative analysis: What it is and how to begin. Research in Nursing \& Health 1995; 18(4):371-375. 
Table I. Demographics and disease severity of the participating patients $(n=61)$

Age

Mean (SD)

$42.4(10.7)$

range

20-70

\section{$\underline{\text { Years since diagnosis }}$}

Mean (SD)

range

Gender

Women

Men

\section{Civil status}

Living alone

Married/cohabitor

$\underline{\text { Disease pattern }}$

Relapsing-remitting

Secondary progressive

Primary progressive

\section{Working capacity}

No influence on working capacity.

MS significantly influence working capacity. 18 (30)

Unable to work due to the infliction of MS. 20 (33)

Retired (age $>65$ )
$5.0(3.4)$

$1-15$

$\underline{\text { n }(\%)}$

$39(64)$

$22(36)$

n $(\%)$

24 (39)

37 (61)

n $(\%)$

37 (61)

17 (28)

7 (11)

n $(\%)$

21 (34)

2 (3) 
Table II. Example of latent content analysis, transforming data into sub-categories, main categories and an underlying theme

\begin{tabular}{|c|c|c|c|c|c|}
\hline Meaning unit & Condensed meaning unit & Code & Sub-category & Main category & Theme \\
\hline $\begin{array}{l}\text { You choose to stay at home and you } \\
\text { don't follow others either. You hardly } \\
\text { dare to test if you are still able to walk a } \\
\text { little in the woods. It's funny and so has } \\
\text { daily life changed and you live with it } \\
\text { every day. You have this naïve dream } \\
\text { that you should wake up one day and } \\
\text { everything is as before. // If you don't } \\
\text { have the strength you get disappointed } \\
\text { since you think you can do so much. } \\
\text { This you have to accept but it is hard ... }\end{array}$ & $\begin{array}{l}\text { If the patient cannot really } \\
\text { walk in the woods anymore, } \\
\text { she now avoids it. // Nursing } \\
\text { a naïve dream that someday } \\
\text { she will wake up as a healthy } \\
\text { person. It is hard to accept } \\
\text { that her stamina is lacking, } \\
\text { she gets very tired and } \\
\text { disappointed. }\end{array}$ & $\begin{array}{l}\text { Hard to accept } \\
\text { illness-related } \\
\text { limitations in daily } \\
\text { life }\end{array}$ & $\begin{array}{l}\text { Physical } \\
\text { limitations } \\
\text { affecting quality } \\
\text { of life }\end{array}$ & $\begin{array}{l}\text { Experience of ill } \\
\text { health }\end{array}$ & \multirow{2}{*}{$\begin{array}{l}\text { Fighting a } \\
\text { losing battle } \\
\text { but also } \\
\text { gradually } \\
\text { conquering } \\
\text { oneself }\end{array}$} \\
\hline $\begin{array}{l}\text { Re-valuates things. I have been more } \\
\text { observant on such matters now, before } \\
\text { you took life for granted, having certain } \\
\text { things. If I hadn't had this [MS] I don't } \\
\text { think I'd have been attentive to take } \\
\text { advantage of [life] and think a little bit } \\
\text { extra. This is the difference. When you } \\
\text { are healthy with no troubles you don't } \\
\text { even think about these matters, life just } \\
\text { moves on. You take so much for } \\
\text { granted, run your own race. But it's not } \\
\text { negative to re-evaluate [things]. }\end{array}$ & $\begin{array}{l}\text { Re-evaluates matters. More } \\
\text { attentive, taking things for } \\
\text { granted before. If not for MS, } \\
\text { he would not have been that } \\
\text { regardful of life. Now he } \\
\text { contemplates more. Being } \\
\text { healthy with no problems, } \\
\text { things are taken for granted } \\
\text { and the race of life just } \\
\text { continues. Not negative to re- } \\
\text { evaluate [things]. }\end{array}$ & $\begin{array}{l}\text { Re-evaluates, } \\
\text { observant on matters } \\
\text { previously taken for } \\
\text { granted }\end{array}$ & $\begin{array}{l}\text { Acquiring } \\
\text { illness insight }\end{array}$ & $\begin{array}{l}\text { Experience of } \\
\text { health in spite of } \\
\text { illness }\end{array}$ & \\
\hline
\end{tabular}

